\title{
Correction to: Ground improvement and its role in carbon dioxide reduction: a review
}

\author{
Ahmed Mohammed Awad Mohammed ${ }^{1} \cdot$ Nor Zurairahetty Mohd Yunus ${ }^{1} \cdot$ Muhammad Azril Hezmi $^{1}$. \\ Dayang Zulaika Abang Hasbollah ${ }^{1}$. Ahmad Safuan A Rashid ${ }^{1,2}$
}

Published online: 2 February 2021

(C) Springer-Verlag GmbH Germany, part of Springer Nature 2021

\section{Correction to: Environmental Science and Pollution Research} https://doi.org/10.1007/s11356-021-12392-0

The correct $1^{\text {st }}$ Author name is presented in this paper.

The online version of the original article can be found at https://doi.org/ $10.1007 / \mathrm{s} 11356-021-12392-0$

\section{Ahmad Safuan A Rashid \\ ahmadsafuan@utm.my}

Ahmed Mohammed Awad Mohammed

khatib.kaka@yahoo.com

Nor Zurairahetty Mohd Yunus

nzurairahetty@utm.my

Muhammad Azril Hezmi

azril@utm.my

Dayang Zulaika Abang Hasbollah

dzulaika@utm.my

1 Department of Geotechnics and Transportation, School of Civil

Engineering, Universiti Teknologi Malaysia, 81310 Johor

Bahru, Johor, Malaysia

2 Centre of Tropical Geoengineering, School of Civil Engineering,

Universiti Teknologi Malaysia, Skudai, Johor, Malaysia 